\title{
Teaching $\mathbf{G}$ ame and Simulation Based Probability
}

\section{Timur Koparan (10 $1^{*}$}

${ }^{1}$ Zonguldak Bülent Ecevit University, Ereğli Faculty of Education, Department of Mathematics and Science Education, Zonguldak, Turkey

\section{ARTICLE HISTORY}

Received: 13 November 2018

Revised: 22 April 2019

Accepted: 04 May 2019

\section{KEYWORDS}

Probability teaching,

Educational game,

Simulation,

Experimental probability,

Theoretical probability

\begin{abstract}
Technology and games are the areas where learners are most interested in today's world. If these two can be brought together within the framework of learning objectives, they can be an advantage for teachers and students. This study aims to investigate the learning environment supported by game and simulation. The games were used to evaluate the basic probability knowledge of the prospective teachers, to demonstrate the role of problem solving in the formation of the mathematical knowledge, and to enable discussing mathematical ideas in a worksheet. Simulations were used for visualization and a large number of experiments. The sampling of the study, by which case study research is adopted, is comprised of 40 prospective teachers at a state university in Turkey. The data were collected by introducing nine open-ended questions by means of games, worksheets and simulation activities. The questions asked relevant to the games include making predictions about the fairness of the games, playing the games in small numbers and in big numbers and the observation of the scores, calculation of the winning probabilities of the gamers both experimentally and theoretically, and their comparisons. The process of finding out the probability information underlying the games by the prospective teachers was analyzed qualitatively by means of worksheets, simulations and in-class observation, and the ways of thinking, intuitions, estimations, strategies, and opinions about the learning situation of the participants were tried to be determined. The results obtained put forward that the learning situation that was set up simultaneously contributed to the knowledge of probability and probability teaching of the prospective teachers; and that the candidates' opinions about the learning situation are positive.
\end{abstract}

\section{INTRODUCTION}

Probability includes a lot of disciplines (physics, economics, meteorology, genetics, insurance) due to having a wide range of application. Furthermore, the language of probability has come into most part of our daily lives. For instance, the probabilities of the side effects of a medicine, home accidents, raining, chance games, sports competitions, Gal (2005) claim that needs in the real world are supposed to be part of the thought inclining, the things thought at school, assessed

CONTACT: Timur KOPARAN $₫$ timurkoparan@gmail.com Zonguldak Bülent Ecevit University, Ereğli Faculty of Education, Department of Mathematics and Science Education, Zonguldak, Turkey 
and valued. In this point of view, since individuals come across situations of uncertainty a lot of times and in a lot of places in everyday life, probability has gained importance as a content area in which students should have experience so as to become knowledgeable citizens from the school years. Probability teaching can increase people's levels of interpreting what they see. That's why probability has reached a more important status in the teaching programs of many countries recently (National Council of Teachers of Mathematics, 2000; Koparan \& Kaleli Y1lmaz, 2015). However, probability is a subject which students have difficulty in learning (Ben Zvi \& Garfield, 2004; Koparan \& Kaleli Yılmaz, 2015; Koparan \& Taylan Koparan; 2019). Another difficulty for teaching probability is the fact that intuitions and truths aren't concordant. In probability teaching, sufficient education and support are needed in order to develop the intuitions of both teachers and students (Batanero, Contreras, Fernandez \& Ojeda, 2010). However, such deficiencies as the fact that subjects are generally discussed in teacher centered class situations; that suitable teaching material is missing (Gürbüz, 2006); and that most of mathematics teachers are unqualified to teach probability actively (Bulut, Yetkin, \& Kazak, 2002) require studies on developing and applying teaching material and methods, and evaluating the applications in this respect. Since visuality needed for probability problems can't be provided in traditional situations, there is need for alternative learning situations (Koparan, 2019). Using games and simulations are some of these alternative situations.

\subsection{G ame-Based Learning}

Games have always played an important role in learning mathematics as they encourage mathematical thinking (Kamii \& Rummelsburg, 2008). Teachers know that the situations in which students learn by doing and experiencing are more valuable. This is closely connected with learning by discovering. However, this is a hard educational problem and teachers usually fail to fulfill it. Games are good examples of learning together in the learning situation

(Bragg, 2007). Learning takes place in a context. For the students, games immediately become useful in learning. Because, there is an attempt to play the game and to contribute to play it better. There are some studies revealing that game-based learning enriches the learning environment, improves the students 'performance, increases the students' motivation, provides the opportunity to work with the group and provides a fun learning environment (Hamalainen, 2008; Nisbet ve Williams, 2009; Burguillo, 2010; Ahmad et al., 2010; Gürbüz et al., 2014)

In this study, the games were used to evaluate the basic probability knowledge of the prospective teachers, to demonstrate the role of problem solving in the formation of the mathematical knowledge, and to enable discussing mathematical ideas.

\subsection{Using Simulations in Probability Teaching}

The potential which dynamic statistical software has can be used to establish learning situations suitable for both teachers and students (Koparan, 2015; Koparan \& Kaleli Y1lmaz, 2015; Koparan \& Taylan Koparan, 2019). Upon the increase in the importance of the subject of probability in teaching programs and access to technology at schools, and on the purpose for teachers to have students to experience repeated trials of the same event, using concrete material and experiments through computer simulations should be encouraged (Batanero, Henry, \& Parzysz, 2005). Therefore, students need experimental research to understand the theoretical bases of probability. The experimental research is an opportunity to improve their stochastic intuitions, to help them establish a sound understanding of probability, and to motivate them (Borovcnik \& Kapadia, 2009). The studies carried out on probability teaching have recommended using computers as a way to understand abstract or difficult concepts and to increase students' talents (Mills, 2002; GAISE, 2005; Gürbüz, 2008; Koparan, 2015; Koparan, 2016). Batanero, Henry and Parzysz (2005) emphasize that students should execute the simulations to help them solve simple probability problems which are impossible through 
physical experiments in computer courses at schools. Simulation is the most suitable strategy in focusing better on concepts and in decreasing technical computations (Borovcnik \& Kapadia, 2009). Simulations provide an opportunity to strengthen understanding statistical ideas (Konold, Harradine, \& Kazak, 2007) and to support the students' process of learning while studying experiments of chance (Maxara \& Biehler, 2007).

Along with the development in technology, thanks to some software, modeling mathematical situations has become easier. So, the students, who have been motivated by means of experiments, can research and discover theoretical solutions. Furthermore, they can be convinced about the theoretical solution model by comparing the theoretical and experimental solutions of a problem. Some researchers have stated that modeling strengthens the applicability of mathematical ides in life, learning new mathematical concepts and stochastic intuitions, and contribute to understanding mathematical concepts (Maxara \& Biehler, 2007; Koparan, 2016). Moreover, experimental and theoretical probabilities should be tied up. That is, modeling should offer the advantage of understanding how algebraic facts influence the observed situations.

The simulation based approach requires a special learning attempt for both teachers and students. Since they require not only a statistical perspective but also modeling skills. But most teachers have very little experience about carrying out experiments of probability and using instruments of simulation, and they might have difficulty in the application of the experimental approach (Stohl, 2005). That's why, there is need to put forward new approaches relevant to probability teaching. The modeling of probability may enable the connection between the real world and mathematics (Greer \& Mukhopadhyay, 2005). Beg (1995) points out that modeling in statistics provides an ideal teaching platform for mathematical discoveries due to execution with pictorial and concrete material instead of equations and graphics.

Hawkins (1990) points out that probability teaching can't be reduced to conceptual structures and tools of problem solving only, also, there is obligation to generate ways of logical inference and right intuitions in students. Not only does probability teaching offer different models but also it ensures thinking about such questions in deep as how to get information from sources, or why a model is suitable. Prospective teachers don't take the courses of probability and statistics before the third grade at the university. Unfortunately, teachers aren't always able to have a good preparation period to teach probability during their initial training because of time pressure as well. More research is needed so as to clarify the basic components in probability teaching at every level and the preparation of teachers. In recent years, important research that focused on the education of teaching of mathematics and professional development (Ponte \& Chapman, 2006; Hill, Sleep, Lewis, \& Ball, 2007) hasn't been redounded on teaching of statistics and probability. This denotes that teaching of statistics and probability is an important research area needing to be developed at school level.

There have been different viewpoints about what the best probability teaching should be so that they can be interpreted by everyone in different situations (Jones, Langrall, \& Mooney, 2007). These viewpoints depend on different interpretations of probability. People think of probability in at least three different ways (classical, frequent and subjective) and these viewpoints may appear in the process of teaching and learning. Each of these interpretations has advantages and disadvantages (Batanero, Henry, \& Parzysz, 2005). If students need to develop a significant sense about probability, it is of importance for them to accept these different interpretations, and to discover the connections among them and different contexts through which one of them might be useful.

By this study, it was aimed to offer games containing contingent situations to prospective teachers; to get predictions made about the games; to observe the games for few trials and to make experimental probability calculations using simulations for multiple trials; to design such 
a learning situation as to enable to put forward relations and models to help to understand theoretical solutions; and to evaluate that learning situation. In accordance with this aim, games based activities were developed by the researcher about probability teaching and those activities were supported by worksheets and simulations. It was thought that the activities, which contained games, predictions, experiments, observation and discussion, would reveal the knowledge of the prospective teachers about the probability buried in the games; and that, besides, they would offer samples of the contents of teaching needed in probability teaching and the use of technology in probability teaching. This study is also going to try to find answers to the questions about how to integrate the use of games and simulations with probability teaching. In accordance with these aims, the problem of research was specified as "What are the efficacy of the use of games and simulations in probability teaching and the opinions of the prospective teachers about it?".

\subsection{Conceptual framework}

The games based activities executed in this study are based on the Strategy of Predict, Observe and Explain (POE). The POE strategy was developed by White and Gunstone (1992) to expose students' predictions and reasons for what they did for a particular event. There are three steps in POE strategy.

Step 1. Predict Students are asked to write their predictions about what will happen.

Step 2 Observe Time is given for experiment and observation. Students are asked to write down what they observe.

Step 3. Explain: They are asked to think again and take into account the observation. After the students write their explanations on their papers, they discuss their ideas together.

In this study, the prospective teachers were asked to make predictions about the game before playing it. Later, at the observation stage, the games are played with few trials and the gamers think of what to do to win the game. Then, observation was carried out to review the results of multiple trials using simulations. And at the explain stage, which is the final stage, it was aimed to focus on the theoretical solutions and compare the experimental results to the theoretical ones.

Understanding the initial ideas of learners in probability teaching may be used to inform teachers about the ways of thinking of learners; to produce discussions and to motivate students to learn (Joyce, 2006). Surprising cases create situations in which students can be ready to revise their personal theories. The strategy is based on the following principles:

1. If students aren't asked for predictions about what to happen in the problems, it may not be possible to observe them carefully.

2. Writing their predictions motivates students to learn the answer.

3. Asking students to explain the reasons of their predictions gives teachers their understanding. This may be useful in case of misunderstandings to happen and to improve the understanding they have.

4. Explaining and evaluating their predictions, and hearing others' predictions help students start to evaluate their learning and build new meanings.

In this study, it was thought that it would be appropriate to use POE strategy, which provides the opportunity of re-examining their own theories, revealing the current understanding of prospective teachers. At the same time the POE is a strategy compatible with the constructivist learning theory (Küçüközer, 2013). 


\section{MATERIAL and METHOD}

In this study, case study research was used. The sampling of the study is comprised of 40 (28 girls and 12 boys) volunteering prospective mathematics teachers studying in a class of totally 60 (45 girls and 15 boys) prospective teachers at a state university. The prospective teachers did those activities in the scope of the statistics and probability course for the first time along with their university life. They have encountered "TinkerPlots Sampler Tool" (Konold \& Miller, 2004) last year in Teaching Technology and Material Development Course. However, they only applied data analysis and basic statistical concepts. The prospective teachers had had no experience of probabilistic problems and modeling studies until this study.

\subsection{Data collection tools}

In this study, games supported by worksheets, in class observations carried out by the researcher, simulation sections made up by means of dynamic software, and an evaluation form to determine the prospective teachers' opinions were used as means of data collection. The opinions of a specialist who gave the probability course in the selection of the games and formation of the evaluation form were obtained. The six games played by the prospective teachers and the questions about each game are presented in tables under the title of findings. The nine open ended questions in the evaluation form aiming to find out the prospective teachers' opinions are also presented in the findings part. During the activities, the researcher made participant observation.

\subsection{Procedure}

In this study, the worksheets developed by the researcher and the simulations developed using TinkerPlots, a software of dynamic statistics, were used as the data collection instruments. The researcher is also a faculty member teaching the prospective teachers probability statistics. They were informed about TinkerPlots 2.3.2 Sampler and how to make simulations for 4 class hours prior to the study. The activities of probability teaching through games lasted 6 six weeks as to 2 hours per week in extra-curricular times. The groups of two were selected randomly for the games. The worksheets were handed out to the groups and the games were introduced. The gamers were asked to write down their predictions about the game. Later, the game was played by the gamers using few dices or less money ( 20 or 50). After they had played the game, the gamers were asked to make predictions again. And after that, the prospective teachers were asked to prepare a simulation about the game, to use the simulation for multiple trials, and to compute the experimental probability. And finally, they were asked to make a theoretical probability calculation and compare the experimental and theoretical probability results. At the end of the six-week period, the prospective teachers were asked their opinions about the use of simulation supported games in probability teaching.

\subsection{Data analysis}

The ways of thinking of the prospective teachers about the games were tried to put forward by qualitatively analyzing the data obtained from the worksheets and observations. Some opinions were supported by the simulations made by the prospective teachers. The opinions about the games were also qualitatively analyzed and the outstanding opinions were presented directly with the quotations. The researcher observed the processes of making predictions, playing games, making experimental probability calculations and creating simulation models, using them and passing them to the theoretical calculations. The answers given to the nine open ended questions were analyzed in determining the opinions of the prospective teachers for the game and simulation based learning environment. The answers given to each question are examined and classified into similar and different ideas. 


\section{RESULTS}

In this research, the results were presented under two titles as those obtained from the games and simulations and from the prospective teachers' opinions about the use of games and simulations. The findings obtained from the games and simulations contain the prospective teachers' predictions, observations and explanations, and the simulation sections. And the findings obtained from the prospective teachers' opinions about the use of games and simulations contain the qualitative analysis of the answers to the nine open ended questions in the evaluation form.

\subsection{The findings obtained from the games and simulations}

In this part, the findings obtained from the worksheets and the simulation sections about each game are presented altogether. On the worksheets, the predictions by the prospective teachers about the games, the observations and experimental probability calculations for the few and multiple trials, and in the explanations part, the results about the theoretical probability calculations and the ways of thinking were focused on. And in the simulation sections, the process of the simulation made by the prospective teachers was tried to be revealed.

Table 1. The rock paper-scissors-game

\begin{tabular}{|c|c|}
\hline The rule of the game & The questions about the game \\
\hline $\begin{array}{l}\text { The game is named as "hands game". Because, both } \\
\text { gamers use hand signs while playing the game. The } \\
\text { hand signs are as follows: } \\
\text { Fist: Stone } \\
\text { Palm: Paper } \\
\text { Index \& Middle Fingers: Scissors } \\
\text { While playing, hands are moved saying stone, paper, } \\
\text { scissors and one of them is } \\
\text { chosen at the } 4^{\text {th }} \text { motion. } \\
\text { The meanings of the } \\
\text { probable } 3 \text { scores are: } \\
\text { Stone breaks scissors. } \\
\text { Paper wraps stone. } \\
\text { Scissors cut paper. }\end{array}$ & $\begin{array}{l}\text { Think whether the game Stone-Paper-Scissors } \\
\text { is fair after playing it. That is, is the chance to } \\
\text { win for every gamer equal? In order to } \\
\text { understand whether the game is fair, make a } \\
\text { tree diagram or a list of the probable scores, } \\
\text { and also the list of the winners. How many } \\
\text { probable scores are there? } \\
\text { How many choices can the } 1^{\text {st }} \text { gamer make? } \\
\text { How many choices can the } 2^{\text {nd }} \text { gamer make? } \\
\text { What is the multiplication of these two scores? } \\
\text { Compare the multiplication and the number of } \\
\text { the probable scores. Compare the winning } \\
\text { numbers of the Stone-Paper-Scissors game. } \\
\text { Decide whether the game is fair. }\end{array}$ \\
\hline
\end{tabular}

Predict: When the predictions were examined before beginning the game in Table 1, it was seen that, of the prospective teachers, 35 said that the game was fair and 15 not. Some statements about these opinions are presented below.

"I think it isn't fair. Winning depends on the move you do at the last moment."

"It isn't fair. You can't know what the opponent is doing. It depends on chance."

"I think it isn't fair. Because there will be many cases in which the game ends in a draw."

"The cases in which the game ends in a draw are many, but the number of the cases when stone, paper or scissors wins will be equal. That's why the game is fair."

"Stone, paper or scissors won't have the upper hand against one another. Their theoretical probabilities are equal. The probability that the game ends in a draw is a little bigger than these."

Observe: The prospective teachers played the game twenty times and made experimental probability calculations. Later, they were asked to make models for multiple trials. In Figure 1, the model made can be seen. 


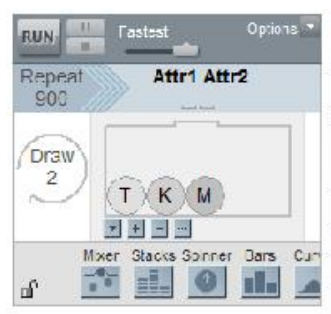

\begin{tabular}{|c|c|c|c|c|c|}
\hline \multicolumn{5}{|c|}{ Results of samoler 1} & Optione: \\
\hline & JoIn & Attr1 & Attr2 & combın... & Formula \\
\hline ᄂor & $\square$ & $\square$ & $\square$ & $\square$ & $\square$ \\
\hline 800 & $\pi, \pi$ & $n$ & $\pi$ & $n, n$ & 0 \\
\hline 881 & K: & K & 1 & K:I & K \\
\hline 882 & $k ; k$ & K & $\mathrm{K}$ & K K & B \\
\hline 883 & $T, M$ & $T$ & M & $\mathrm{M} ; \mathrm{T}$ & $T$ \\
\hline 884 & $\mathrm{~T}: \mathrm{T}$ & $T$ & $T$ & $T: T$ & D \\
\hline 885 & $K, K$ & $k$ & $k$ & KK & B \\
\hline 886 & $\mathrm{~K}: \mathrm{M}$ & K & M & K.N & M \\
\hline 887 & $\mathrm{~T}: \mathrm{T}$ & $T$ & $T$ & $T: T$ & A \\
\hline 888 & $T ; T$ & $T$ & $\begin{array}{lll}T & \\
\end{array}$ & $T \cdot T$ & B \\
\hline 889 & MI:K & M & K & K.N & M \\
\hline 890 & $K ; T$ & K & $T$ & $K T$ & K \\
\hline 891 & $K ; T$ & $k$ & $T$ & $K T$ & K \\
\hline 892 & $K M M$ & K & M & $\mathrm{KN}$ & M \\
\hline 893 & $K, M$ & $k$ & M & K.N & M \\
\hline 894 & $1: 1$ & I & 1 & 1:1 & $B$ \\
\hline 895 & $T: M$ & $T$ & IA & $M ; T$ & $T$ \\
\hline 896 & $\mathrm{~K}, \mathrm{~K}$ & K & $\kappa$ & $\mathrm{KK}$ & B \\
\hline 897 & $\mathrm{~T}: \mathrm{T}$ & $T$ & $T$ & $\mathrm{~T}: T$ & D \\
\hline 898 & $K, M$ & K & M & K. I I & M \\
\hline 899 & $1: 1$ & 1 & 1 & 1:1 & $B$ \\
\hline 900 & $T: M$ & $T$ & M & $\mathrm{M} ; \mathrm{T}$ & $T$ \\
\hline
\end{tabular}

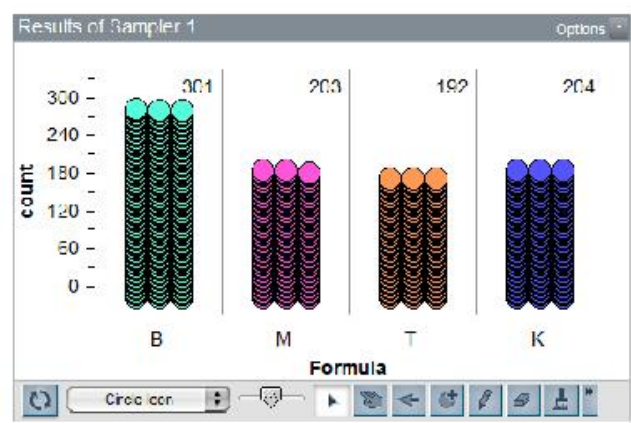

Figure 1. The simulation model made for the stone paper scissors game.

The sampler on the left in Figure 1 is the simulation model made for the stone paper scissors game. $\mathrm{T}$ stands for stone, $\mathrm{K}$ for paper and $\mathrm{M}$ for scissors. It is displayed that, by Draw 2, two of the stone, paper and scissors can be selected randomly, and by Repeat 900, the game can be repeated 900 times. In the figure in the middle, Attr1 displays the moves of the $1^{\text {st }}$ gamer and Attr2 displays the moves of the $2^{\text {nd }}$ gamer, and Formula displays the winning move. Finally, result of Sampler 1 displays the winning numbers of stone, paper and scissors and the draws.

Explain: The prospective teachers filled in the tree diagram in the worksheet after the predictions and calculated the theoretical probabilities. In Figure 2, the tree diagram and the calculations of theoretical probabilities can be seen.

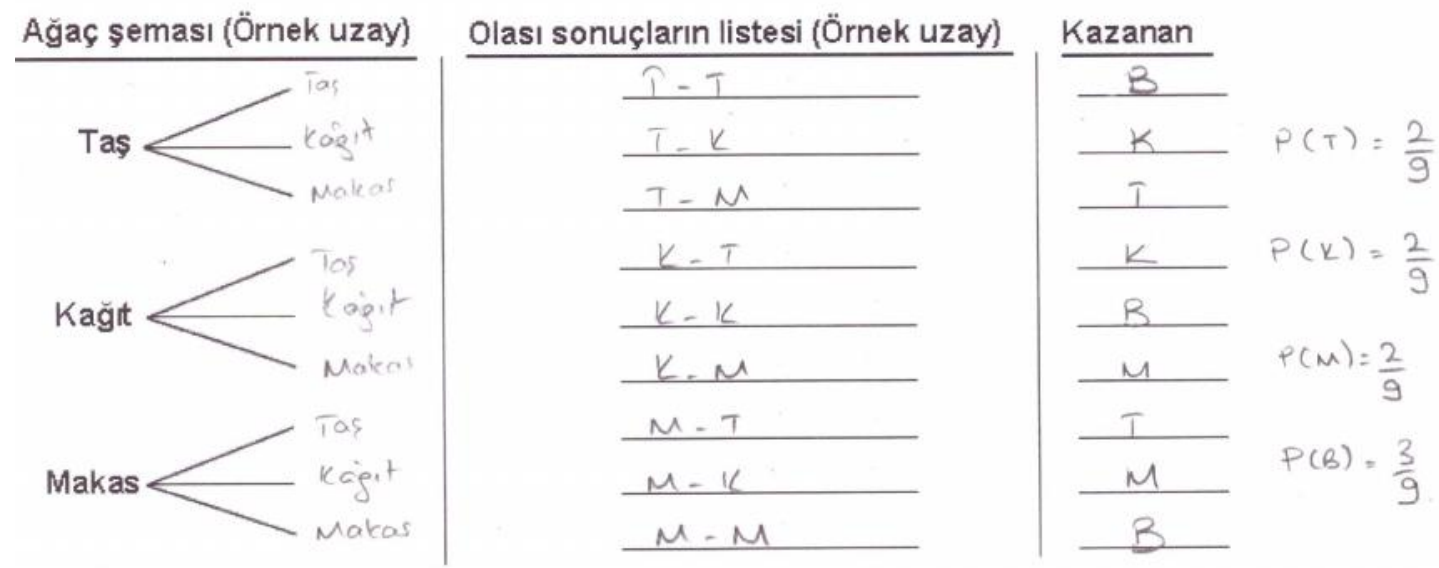

Figure 2. The tree diagram completed by the prospective teachers in the worksheet of the stone paper scissors game.

As can be seen in Figure 2, the prospective teachers fulfilled the directive on the worksheet and filled in the gaps. The worksheet enabled the prospective teachers to see more clearly all of the probable scores and the number of the desired situations. Thus, the theoretical probabilities were calculated correctly. The mathematical facts underlying the experimental calculations were understood much better. 
Table 2. The difference of the dices game

The rule of the game

The questions about the game

Two friends decide to play a dice tossing game. They throw two dices and find the difference between the dices by extracting the smaller number from the bigger one. If the difference is 0,1 or 2 , the first gamer, or $3,4,5$, the $2^{\text {nd }}$ gamer wins.

Do you think this game is fair? Explain your predict. Play the game with your friend next to you 50 times. Record the scores in the table. Has your opinion about the equity of the game changed after playing it? If it has, how? What have you noticed after playing the game and seeing the scores which you didn't before? Please, calculate the winning probabilities of the gamers theoretically.

Predict: When the predictions were examined before beginning the game in Table 2, whose rules are given, it was seen that, of the prospective teachers, 24 said that the game was fair and 26 not. Some statements about these opinions are presented below.

"I think the game is fair. Because, there are 3 situations for both gamers - 0,1,2 for the first and 3,4,5 for the second. So, I think it is fair."

"It is fair, because, I think the difference will be equal in probability."

"It is fair, because, the differ ence between the numbers will be the same."

"It isn't, because the probability for the difference to be small is less. E.g. there are two situations for 5 to come but ten for $1 . "$

Observe: The prospective teachers played the game 50 times and made experimental probability calculations. Later, they were asked to make models for multiple trials. In Figure 3, the model made can be seen.
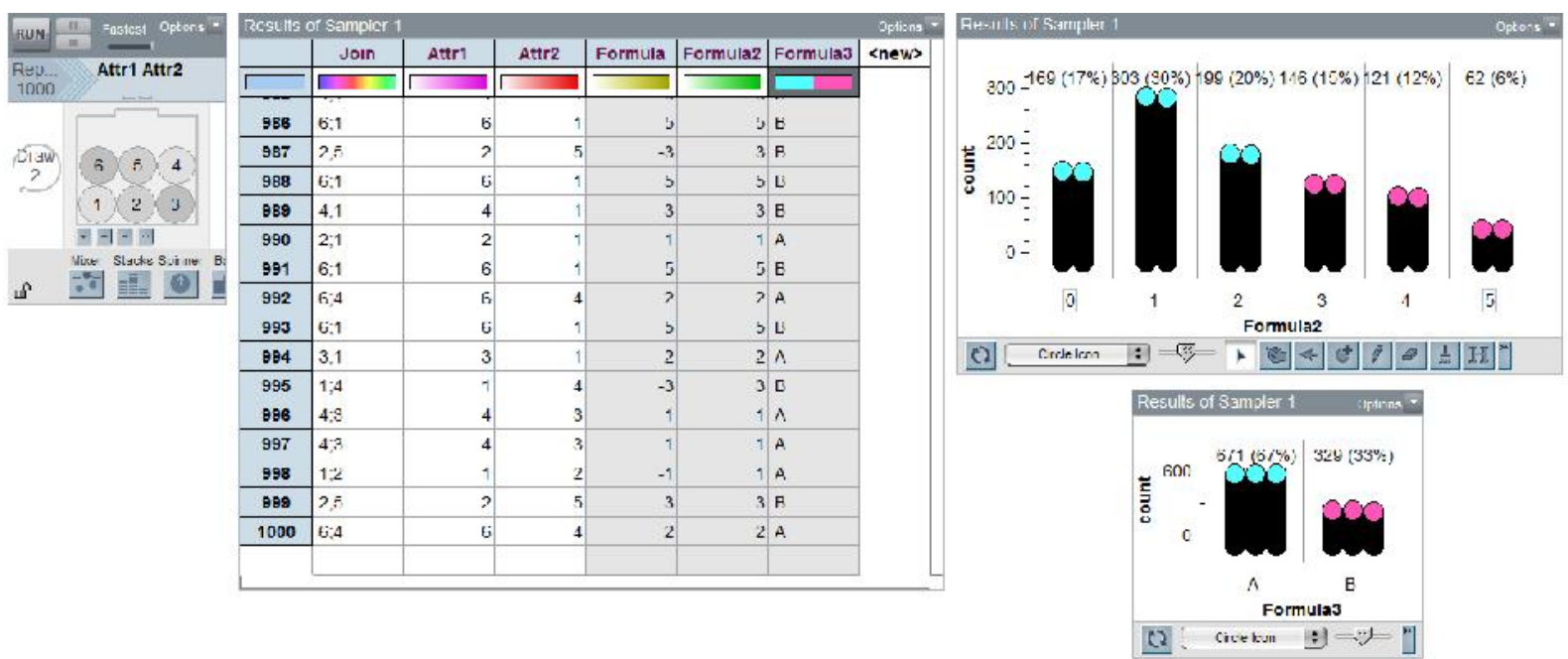

Figure 3. The simulation model made for the difference of the dices game.

The sampler on the left in Figure 3 is the simulation model made for the difference of the dices game. It is displayed that, by Draw 2, two of the numbers 1,2,3,4,5 can be selected randomly, and by Repeat 1000, the trial can be repeated 1000 times. In the figure in the middle, Attr1 displays the $1^{\text {st }}$ dice and Attr 2 displays the $2^{\text {nd }}$ one, Formula 1 displays the difference of the dices, Formula 2 displays the absolute value of the difference of the dices, and Formula 3 displays the winning status of the gamers A and B. While Result of Sampler 1 displays the 
distribution of the difference of the dices in consequence with 1000 trials, the graphic lower right hand displays the winning numbers and percentages of the gamers A and B.

Explain: The probability information underlying the game was asked at the end of the few and multiple trials, and they were asked to calculate the theoretical probability. Some situations and ways of thinking are presented below.

Some students calculated the probabilities wrongly because they counted the situations wrongly, e.g. 23/36 and 13/36, 3/5 and 2/5 etc. It was seen that some of them got the wrong result because they didn't take the permutation of the dices into consideration. E.g.,

In order for the difference of the dices to be 0 , they must come $(6,6),(5,5),(4,4),(3,3)$ $(2,2),(1,1)$, to be $1,(6,5),(5,4),(4,3),(3,2),(2,1)$, to be $2,(6,4),(5,3),(4,2),(3,1)$, to be $3,(6,3),(5,2),(4,1)$, to be $4,(6,2),(5,1)$, and to be $5,(6,1)$. There are totally 15 conditions for 0,1,2 and 6 conditions for 3,4,5. The probabilities are found to be 15/21.

Some of the prospective teachers were seen to have evaluated all the situations and calculated the probabilities correctly.

In order for the difference of the dices to be 0 , they must come $(6,6),(5,5),(4,4),(3,3)$ $(2,2),(1,1)$, to be $1,(6,5),(5,6),(5,4),(4,5),(4,3),(3,4),(3,2),(2,3),(2,1),(1,2)$, to be $2,(6,4),(4,6),(5,3),(3,5),(4,2),(2,4),(3,1),(1,3)$, to be $3,(6,3),(3,6),(5,2)$, $(2,5),(4,1),(1,4)$, to be $4,(6,2),(2,6),(5,1),(1,5)$, and to be $5,(6,1),(1,6)$. There are totally 24 conditions for $0,1,2$ and 12 conditions for 3,4,5. The probabilities are found to be $24 / 36$ and $12 / 36$.

It was seen that a great majority of the prospective teachers changed their minds after playing the game, and very few were convinced that the game wasn't fair following the theoretical probability calculations.

"Yes, I've changed my opinion. The game isn't fair. M y friend was right."

Table 3. Dart game

The rule of the game

Think that the game in the figure is played by rolling the darts three times. It is thought to make use of a dice so as to simulate the dart scores. It is required 1 point to be won when the dice comes 1 , no point when 2,3 and 4 , and the game to be disregarded when 5 and 6 .

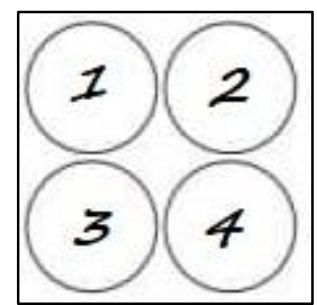

The questions about the game

Is the suggestion suitable for the simulation of the game? Is it useful? Please, explain the reason. Please, predict the probability for a gamer to win 2 points at 3 throws in a dart game. Please, predict how many times a gamer can win 2 points assuming they play the game 50 times. With real trials, please, play the game 50 times. Please, record the scores you have got. Compare your predictions and the scores in the trials. Please, calculate the theoretical probability and compare it to the experimental probability results.

Predict: It was asked whether the suggestion given was suitable before beginning to play the game given in Table 3 in order to simulate the game. Some of the opinions about it are as follows;

"I think it isn't suitable to use a dice. The dice has 6 sides but there are 4 zones in the dart game."

"I think it isn't suitable, because we can hit in the dart game. The dice is a matter of luck, but the dart game is a matter of skill." 
"I think it isn't suitable, because the dice has 6 sides but there are 4 zones on the dart board. That's why it isn't suitable."

"I think it isn't suitable, because we disregard when it comes 5 or 6 and throw it over. We roll it 3 times in some trials and more in some others."

"I think it is suitable, because 1 is a point and 2,3 and mean the missed point, and if it comes 5 or 6 it means to roll it over. There are 4 outputs as a result. It is suitable to use a dice."

"I think it is suitable. If the dart game is played one by one, it takes longer. It has been thought to make use of the dice so that everyone can play simultaneously and the scores can be recorded. It is also suitable to disregard the 5 and 6 sides of the dice and roll it over."

Observe: The prospective teachers played the game 50 times and made experimental probability calculations. Later, they were asked to make models for multiple trials. In Figure 4, the model made can be seen.

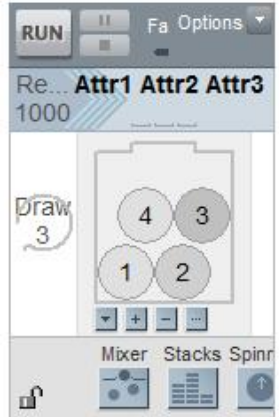

\begin{tabular}{|c|l|r|r|r|r|r|}
\hline & Join & Attr1 & Attr2 & Attr3 & Count_1 \\
\hline & & & & \\
\hline & & & & \\
\hline & & 3 & 2 & 4 & 0 \\
\hline $\mathbf{9 8 5}$ & $3 ; 2 ; 4$ & 2 & 2 & 1 & 1 \\
\hline $\mathbf{9 8 6}$ & $2 ; 2 ; 1$ & 4 & 4 & 4 & 0 \\
\hline $\mathbf{9 8 7}$ & $4 ; 4 ; 4$ & 4 & 1 & 1 & 2 \\
\hline $\mathbf{9 8 8}$ & $4 ; 1 ; 1$ & 4 & 4 & 1 & 1 \\
\hline $\mathbf{9 8 9}$ & $4 ; 4 ; 1$ & 3 & 4 & 4 & 0 \\
\hline $\mathbf{9 9 0}$ & $3 ; 4 ; 4$ & 1 & 3 & 2 & 1 \\
\hline $\mathbf{9 9 1}$ & $1 ; 3 ; 2$ & 4 & 3 & 1 & 1 \\
\hline $\mathbf{9 9 2}$ & $4 ; 3 ; 1$ & 3 & 3 & 1 & 1 \\
\hline $\mathbf{9 9 3}$ & $3 ; 3 ; 1$ & 2 & 1 & 3 & 1 \\
\hline $\mathbf{9 9 4}$ & $2 ; 1 ; 3$ & 4 & 4 & 3 & 0 \\
\hline $\mathbf{9 9 5}$ & $4 ; 4 ; 3$ & 3 & 2 & 2 & 0 \\
\hline $\mathbf{9 9 6}$ & $3 ; 2 ; 2$ & 4 & 3 & 3 & 0 \\
\hline $\mathbf{9 9 7}$ & $4 ; 3 ; 3$ & 3 & 2 & 3 & 0 \\
\hline $\mathbf{9 9 8}$ & $3 ; 2 ; 3$ & 2 & 3 & 3 & 0 \\
\hline $\mathbf{9 9 9}$ & $2 ; 3 ; 3$ & 4 & 1 & 2 & 1 \\
\hline $\mathbf{1 0 0 0}$ & $4 ; 1 ; 2$ & & & & \\
\hline & & & & & & \\
\hline
\end{tabular}

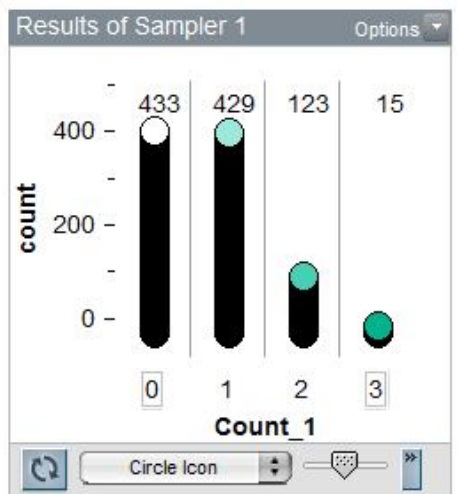

Figure 4. The simulation model made for the difference of the dart game.

The sampler on the left in Figure 4 is the simulation model made for the difference of the dart game. It is displayed that, by Draw 3, three of the numbers 1, 2, 3, 4 can be selected randomly, and by Repeat 1000, the trial can be repeated 1000 times. In the figure in the middle, Attr1, Attr 2 and Attr 3 displays the numbers drawn respectively, and count displays the points gained at a trial. Result of Sampler 1 displays the distribution of the points 0,1,2 and 3 gained at all the trials.

Explain: Following the observation stage, the theoretical probability calculations were performed. Quotes from some of the situations obtained are as follows.

Some of the prospective teachers calculated the probability to win 1 point correctly.

$$
\text { "SSD +SD S+DSS = (1/4.1/4.3/4). 3=9/64=0.14" }
$$

Several prospective teachers calculated the theoretical probabilities of all situations correctly. 
"While calculating the probability to win 0 point out of 3 rolls, 1 should never come. That's to say, it is found that the number of the trios with 2,3 and 4 is $3 \times 3 \times 3=27$, all situations is $4 \times 4 \times 4=64$, the probability is $27 / 64=0.42$. While calculating the probability to win 1 point out of 3 rolls, 1 should come only once. That's to say, there should be such trios as $(1,2,2),(1,3,3)$, $(1,4,4),(1,2,3),(1,2,4),(1,3,4)$. While calculating the first three, a calculation of repeating permutation is performed. Accordingly, the number of all the situations fulfilling the requirement of 1 point is found to be $3+3+3+6+6+6=27$. And the probability is found to be $27 / 64=0.42$. And while calculating the probability to win 2 points out of 3 rolls, $(1,1,2),(1,1,3)$ $(1,1,4)$ situations are in point. There are totally $3+3+3=9$ situations by a calculation of repeating permutation. The probability is found to be $9 / 64=0.14$. The probability to win 3 points out of 3 rolls is a single situation as $(1,1,1)$. The probability is found to be $1 / 64=0.02$."

In Table 4, the experimental and theoretical probability results of a prospective teacher about the points to gain in a dart game can be seen.

Table 4. The experimental and theoretical probability results of a prospective teacher about the points to gain in a dart game.

\begin{tabular}{lcccc}
\hline Approaches & 0 point & 1 point & 2 points & 3 points \\
\hline $\begin{array}{l}\text { Experimental } \\
\text { probability }\end{array}$ & 0.30 & 0.56 & 0.10 & 0.06 \\
$\begin{array}{l}\text { Theoretical } \\
\text { probability }\end{array}$ & 0.42 & 0.42 & 0.14 & 0.02 \\
\hline
\end{tabular}

When the worksheets were reviewed at the end of the study, it was seen that 40 prospective teachers had calculated the theoretical probability correctly, that six of them had calculated it incorrectly, and that 4 of them had only calculated the experimental probability, not the theoretical one.

Table 5. Basketball game

\begin{tabular}{ll}
\hline The rule of the game & The questions about the game \\
\hline $\begin{array}{l}\text { A basketball player scores averagely } 3 \text { of every } 4 \\
\text { shots. In other words, he has a chance of } 75 \% \text { at suitable to use a coin to simulate this } \\
\text { problem? } \\
\text { every shot. }\end{array}$ & $\begin{array}{l}\text { Would it be suitable to use a dice assuming that } \\
1,2 \text { and } 3 \text { are shots on target, } 4 \text { is the missed } \\
\text { shot, and } 5 \text { and } 6 \text { are the disregarded shots? }\end{array}$ \\
$\begin{array}{l}\text { Please, calculate the probability for the } \\
\text { basketball player to score all } 6 \text { or } 5 \text { of the } 6 \\
\text { shots he throws according to the results you } \\
\text { will obtain for 50 trials. Calculate it } \\
\text { theoretically. Compare it to the experimental } \\
\text { results. }\end{array}$ \\
\hline
\end{tabular}

Predict: It was seen that there were both positive and negative opinions about using a coin or a dice in order to simulate the game in Table 5. Some of the quotes about these opinions are as follows:

"A coin is suitable, because he either can or can't score every shot. There are two situations."

"A coin produces outputs with equal probabilities. It is either heads or tails. Since 3 of the 4 shots in this game will be scores, there won't be outputs with equal probabilities. That's why a coin can't be used in the simulation of this problem. I think a dice is suitable."

"What can be the connection between a dice and a basketball player? I think it isn't suitable."

"Since the sample space is different, I think it isn't suitable." 
O bserve: The prospective teachers played the game 50 times with their partners and calculated the experimental probability according to the results they got. One of the experimental results is shown in Figure 5.

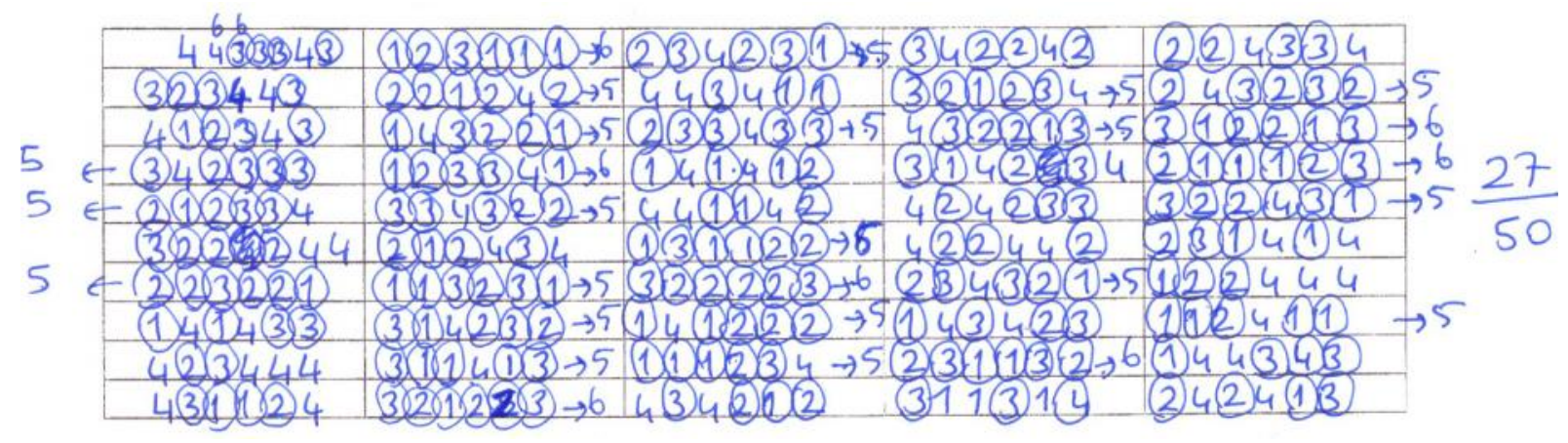

Figure 5. The sample experimental study by the prospective teachers for the basketball game (50 trials)

While the experimental results change between $23 / 50$ and 35/50, it was observed that the values 26/50 and 27/50 were more. In Figure 5, the results of 50 trials are shown. As can be seen in Figure 5, 27 out of 50 trials with a single dice resulted in 5 or 6 scores. It was obtained that the probability for the basketball player to score 5 or all 6 of 6 shots was experimentally $27 / 50=0,54$. The simulation model made to do more trials is shown in Figure 6.

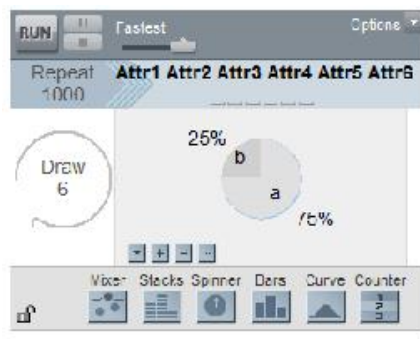

\begin{tabular}{|c|c|c|c|c|c|c|c|c|}
\hline \multicolumn{9}{|c|}{ Resu ts or Sarnpler 1} \\
\hline & Join & Attr1 & Attr2 & Attr3 & Attr 4 & Attr5 & Attr6 & Count_a \\
\hline$\square$ & 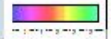 & $\square$ & $\square$ & $\square$ & $\square$ & $\square$ & $\square$ & $\square$ \\
\hline 983 & $a ; a ; a ; a ; 0 ; a$ & a & a & a & a & b & a & 5 \\
\hline 984 & คคว ค, ค; ค & न & a & a & a & ค & a & fi \\
\hline 985 & $b_{1}, d, a, d, a, d$ & 0 & a & $\therefore$ & d & a & a & 5 \\
\hline 986 & a:a:b;a;a;a & $a$ & a & 0 & a & a & a & 0 \\
\hline 987 & $a ; a ; a ; a ; a, b$ & $\Xi$ & a & a & $a$ & a & b & 5 \\
\hline 988 & $b \cdot b ; a ; b ; a ; b$ & 0 & D & 3 & D & a & D & 2 \\
\hline 989 & $a, b ; a ; a$ & न & a & b & a & a & a & 5 \\
\hline 990 & $d a, a, b, a, d$ & $\approx$ & a & $\therefore$ & $\mathrm{v}$ & a & a & 5 \\
\hline 991 & a:a:a:b;a;a & a & a & a & b & a & $a$ & 5 \\
\hline 992 & $a ; a ; a ; a ; b ; a$ & 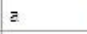 & a & $a$ & a & b & a & 5 \\
\hline 983 & a:a;a;a;a;a & a & a & a & a & a & a & b \\
\hline 994 & 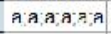 & त & a & A & a & a & ค & fi \\
\hline 995 & $a ; b ; a ; a ; 0 ; a$ & $a$ & D & a & a & b & a & 1 \\
\hline 996 & $a ; a ; a ; a, b$ & a & $a$ & a & a & a & b & 5 \\
\hline 997 & $a ; a ; b ; a ; a ; b$ & $a$ & a & b & $a$ & a & b & 4 \\
\hline 988 & a:a:b:a;a:a & a & a & 0 & a & a & a & o \\
\hline 999 & aหล & न & $\mathrm{b}$ & त & a & ค & a & 5 \\
\hline 1000 & b $; a ; a ; a ; a, b$ & 0 & a & a & a & a & b & 1 \\
\hline
\end{tabular}

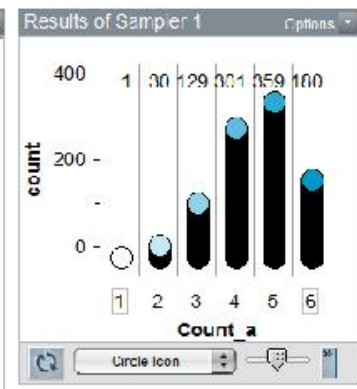

Figure 6. The simulation model made for the basketball game

The sampler on the left in Figure 6 is the simulation model made for the basketball game. It is displayed that, by Draw 6, 6 figures should be produced from the spinner randomly, and by Repeat 1000, the trial can be repeated 1000 times. The figure in the middle indicates the figures produced for each trial and the number of the successful shots at a trial.

Result of Sampler 1 displays the distribution of the successful shots in consequence with all trials. The experimental probability was obtained to be $539 / 1000=0,539$ according to the simulation results.

Explain: Following the observation step, it was proceeded to the theoretical probability calculations. The prospective teachers proceeded to note down all the situations in the 
probability for at least 5 out of 6 shots to be scores and add their probabilities. Below is the section about this solution.

"If the scores are represented by $B$ and the missed shots by $K$, the possible outputs for the theoretical probability will take place as all 6 scores (BBBBBB) and 5 scores ( $K B B B B B, B K B B B B, B B K B B B, B B B K B B, B B B B K B$ and $B B B B B K)$. The probability for all 6 scores is $(0,75)^{6}$

The probability for 5 scores and a missed shot is $(0,75)^{5} .(0,25)$

The theoretical probability according to the Binomial probability distribution is found to be $(0,75)^{6}+6 \cdot(0,75)^{5} \cdot(0,25)=0,5339^{\prime \prime}$

Table 6. Token flipping game

The rule of the game

On the side, you see three tokens one of which has an A and a B, the second an $\mathrm{A}$ and a $\mathrm{C}$, and the third a $\mathrm{B}$ and a $\mathrm{C}$ side. The rules of the game played with these tokens are as follows:

First, who is to be Player 1 and who 2 is decided. Player 1 flips up all the three tokens. When they fall on the ground, if there is any matching, Player 1 wins 1 point. In case of no matching (all three sides of tokens different), Player 2 wins 1 point. The first player to win 20 points wins the game.
The questions about the game

Please, write down your predictions about whether this game is fair. Play this game with your friend until one of you wins 20 points. At every trout, put a line in the winning player's side in the tally. Please, calculate the winning probabilities of players in this game theoretically. Then, compare the experimental and theoretical probability results.

Predict: When the predictions were reviewed before beginning to play the game seen in Table 6 , of the prospective teachers, 23 stated that the game wasn't fair, 8 it wasn't fair and in favor of Player, and 9 it was fair. Some of the quotes about those opinions are as follows:

"I don't think it is fair, because the tokens aren't shuffled."

"I think it is fair, because the probabilities are equal as there are two of every letter."

"The game is very fair."

"The game isn't fair at all."

"It isn't fair. The probability that the token won't match is higher."

"It isn't fair. Player 2 wins."

"I think it isn't fair. Player 1 has more chance."

"The probability for all three to be different is less than two to be the same."

Observe: the prospective teachers played the game with their partners 50 times and calculated the experimental probability according to the results they obtained. Later, they made a model suitable for the problem to make an observation for multiple trials. In Figure 7, the model made is shown.

In Figure 7, the Sampler on the left is the simulation model made for the token flipping game. The first box represents the token with sides $\mathrm{A}$ and $\mathrm{B}$, the $2^{\text {nd }}$ the one with $\mathrm{A}$ and $\mathrm{C}$, and the $3^{\text {rd }}$ the one with B and C. Draw 3, displays that one for each from the boxes should be chosen randomly, and Repeat 1000 displays that the trial should be repeated 1000 times. In the figure in the middle, Attr1, Attr2 and Attr3 display the tokens drawn from the boxes, and in the Formula1 column, 1 indicates that there isn't a match and 2 indicates that there is a match. Result of Sampler 1 displays the numbers of the situations with and without matches in consequence with 1000 trials, that is to say, the winning numbers and percentages of Player 2 and 1 respectively. 


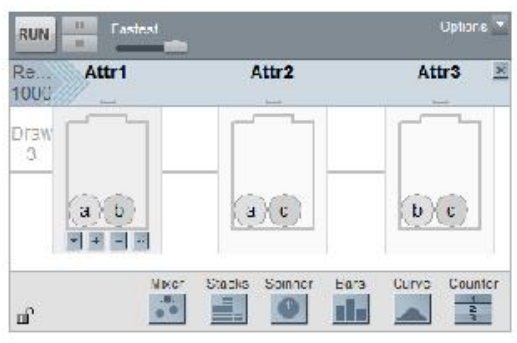

\begin{tabular}{|c|c|c|c|c|c|}
\hline \multicolumn{5}{|c|}{ Results of Sampler 1} & \multirow{2}{*}{$\begin{array}{l}\text { Opilions } \\
\text { Formula }\end{array}$} \\
\hline & Join & Attr1 & Attri2 & Attrs & \\
\hline$\square$ & $\square$ & $\square$ & $\square$ & $\square$ & $\square$ \\
\hline 981 & ก:ค & ? & ค & $\mathrm{n}$ & ; \\
\hline 982 & $a ; a ; b$ & $a$ & a & $b$ & 2 \\
\hline 983 & $a, c, c$ & a & c & c & 2 \\
\hline 984 & $\operatorname{arcc}$ & a & c & c & 2 \\
\hline 985 & $\mathrm{n}, \mathrm{b}$ & $n$ & c. & n & , \\
\hline 986 & $b ; a ; b$ & $b$ & a & b & 2 \\
\hline 987 & $\mathrm{~b} ; \mathrm{a} ; \mathrm{c}$ & $b$ & a & c & 1 \\
\hline 988 & $a, c, c$ & a & c & c & 2 \\
\hline 989 & $n ; n$ & $\pi$ & ค & $n$ & 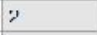 \\
\hline 990 & $\mathrm{a}, \mathrm{a} ; \mathrm{c}$ & $\exists$ & a & c & 2 \\
\hline 991 & $b, c, b$ & b & c & b & 2 \\
\hline 982 & a:3:b & a & a & D & 2 \\
\hline 993 & nCC & $\therefore$ & c. & c. & , \\
\hline 994 & $b ; c ; c$ & $b$ & c & c & 2 \\
\hline 995 & $a, d, c$ & $\therefore$ & a & c & 2 \\
\hline 986 & b: $3 ; \mathrm{C}$ & 0 & a & c & 1 \\
\hline 997 & acc & $\pi$ & s. & c. & y \\
\hline 998 & $a ; a ; b$ & $a$ & a & b & 2 \\
\hline 999 & $\mathbf{a}, \mathrm{c}, \mathrm{b}$ & $\Rightarrow$ & c & v & 1 \\
\hline 1000 & $a, c, c$ & a & c & c & 2 \\
\hline
\end{tabular}

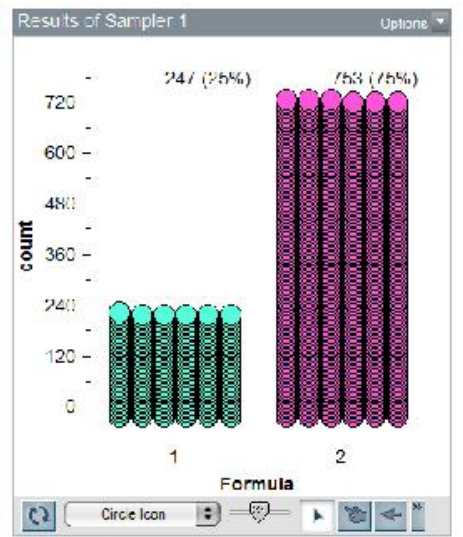

Figure 7. The simulation model made for the token flipping game

Explain: following the observation stage, it was proceeded to the theoretical probability calculations. It was observed that the prospective teachers tried to make up tree diagrams so as to be able to calculate the theoretical probability for the token flipping game. In Table 7, sections from the worksheets are shown.

Table 7. Samples from the tree diagrams made for the token flipping game

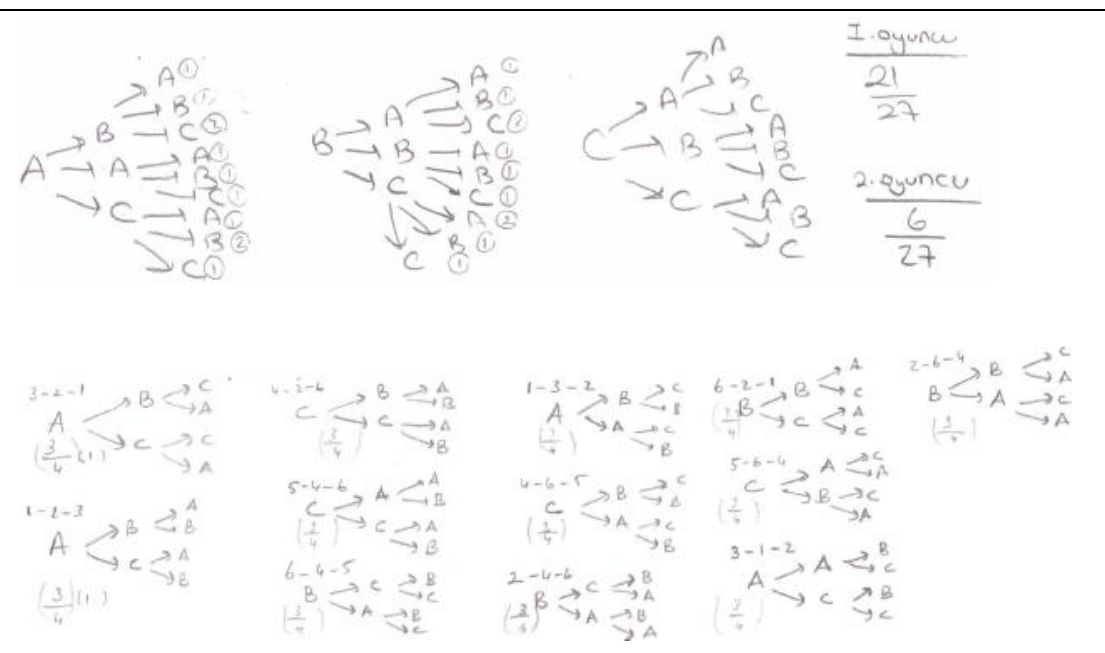

It was seen that some of the prospective teachers made wrong tree diagrams, and thus found wrong theoretical probabilities.

Some of the prospective teachers found out the theoretical probability by enumerating the cards as 1-2-3 and writing down the situations of permutations.

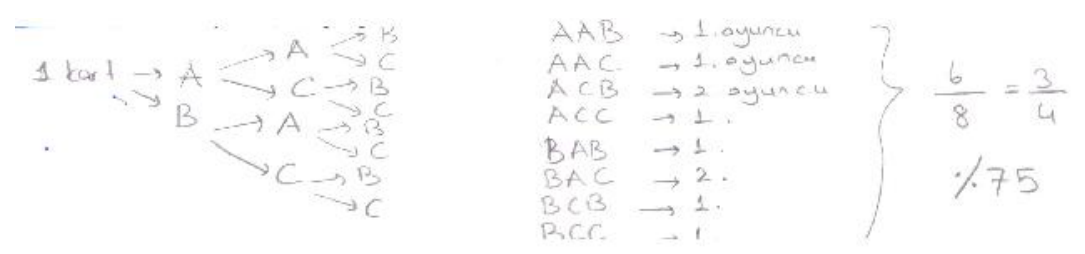

It was seen that some of the prospective teachers found out the result by a single tree diagram. 
Table 8. Blood donation game

\section{The rule of the game}

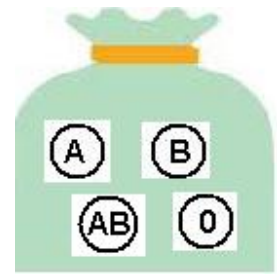

In each of two bags, there are 4 cards with the blood types on. The rule of the game is that those in the $1^{\text {st }}$ bag are donors and those in the $2^{\text {nd }}$ are receptors. When a random card from each bag is drawn, if it is suitable for the first card to donate to the second, player 1, otherwise player 2 wins.

\section{The questions about the game}

Please, write down whether this game is fair, and your predictions.

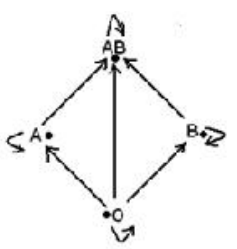

Make use of the correlation of blood donation in the figure and play the game 32 times with your friend. What kind of a situation do you expect as the number of trials increases? Please, write down your opinions. Calculate the theoretical probability. Compare the experimental and theoretical probability results.

Predict: Before beginning to play the blood donation game shown in Table 8, the predictions were reviewed. Of the prospective teachers, 27 said that the game wasn't fair, and 13 it was. Of the participants thinking the game wasn't fair, 14 said the game was in favor of player 1, and 13 in favor of player 2. The quotes about some of the opinions are as follows:

"It's unfair. The probabilities to win will change as to what player 1 draws."

"It's unfair, because the 4 blood types aren't distributed equally."

"It's fair, because there are the same cards in both bags."

"It's fair, ability or inability to donate will be equal."

"I think this game is unfair. Player 1 has more advantages."

"I think it's unfair. The probability for player 2 is bigger. In case of inability to donate, always player 2 will win."

"The probability for player 1 is bigger, because ability to donate is more in all situations."

Observe: The prospective teachers played the game with their partners 32 times and calculated the experimental probability in accordance with the results they got. Later, they made a model suitable to the problem to observe multiple trials. In Figure 8, the model made is shown.

The Sampler on the left in Figure 8 is the simulation model made for the blood donation game. It represents the blood types A, B, 0 and AB. Draw 2, displays that two of them can be chosen randomly, and Repeat 1000 displays the trials will be repeated a 1000 times. In the shape in the middle, Attr 1and Attr2 display the names of the randomly chosen blood types, in the Formula 1 column, D displays the suitable matchings for donation, and $\mathrm{Y}$ unsuitable matchings. Result of Sampler 1 displays the number of incorrect and unsuitable situations according to the result of a 1000 trials, that is to say, the numbers and percentages of player 1 and 2 . 


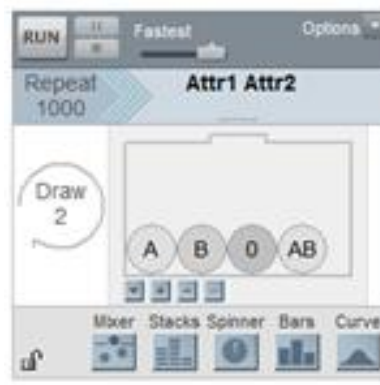

\begin{tabular}{|c|c|c|c|c|c|}
\hline \multicolumn{4}{|c|}{ Results of Sampier 1.} & \multicolumn{2}{|c|}{ Oresone: } \\
\hline & Join & Attri & Attr2 & Formula & $<$ \\
\hline$\square$ & $\square$ & $\square$ & $\square$ & $\square$ & \\
\hline 986 & $A B: B$ & $A B$ & B & $y$ & \\
\hline 987 & BAB & B & $A B$ & D & \\
\hline 988 & $A B A$ & $A B$ & A & $y$ & \\
\hline 989 & BA & B & A & $y$ & \\
\hline 990 & BA & B & A & $\mathrm{Y}$ & \\
\hline 991 & $A B A$ & $A B$ & A & $Y$ & \\
\hline 992 & 0,0 & 0 & 0 & 0 & \\
\hline 993 & B. & B & 0 & $Y$ & \\
\hline 994 & $A B ; B$ & AB & B & $Y$ & \\
\hline 995 & B. B & B & B & D & \\
\hline 996 & $B, 0$ & B & 0 & $y$ & \\
\hline 997 & $A B A$ & $A B$ & A & Y & \\
\hline 998 & $B A B$ & B & $A B$ & D & \\
\hline 999 & AB;A & $A B$ & A & $y$ & \\
\hline 1000 & BA & B & A & $\mathbf{Y}$ & \\
\hline
\end{tabular}

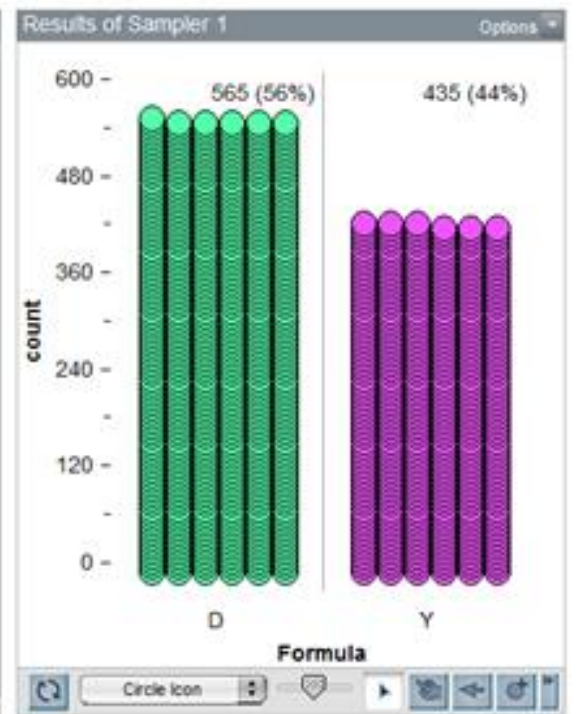

Figure 8. The simulation model made for the blood donation game.

Explain: It was seen that the prospective teachers used different methods to calculate the theoretical probability for the blood donation game. In Table 9, sections from the worksheets are shown.

Table 9. Samples from the diagrams made for the blood donation game

\begin{tabular}{|c|c|c|}
\hline 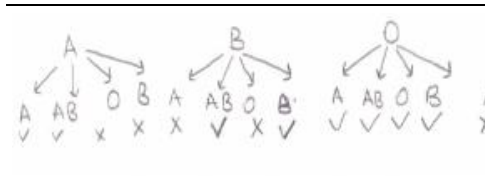 & 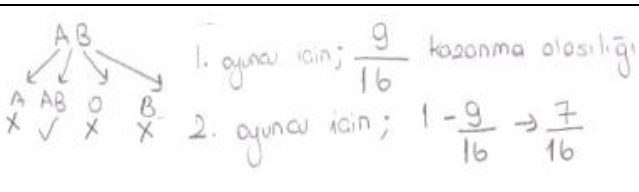 & $\begin{array}{l}\text { Some of the prospective } \\
\text { teachers used the tree } \\
\text { diagram to find out all } \\
\text { situations. }\end{array}$ \\
\hline $\begin{array}{llll}(0, A) & (A, A) & (B, A) & (A B, A) \\
(0, B) & (A, B) & (B, B) & (A B, B) \\
(0,0) & (A, 0) & (B, 0) & (A B, O) \\
(0, A B) & (A, A B) & (B, A B) & (A, B, A B)\end{array}$ & 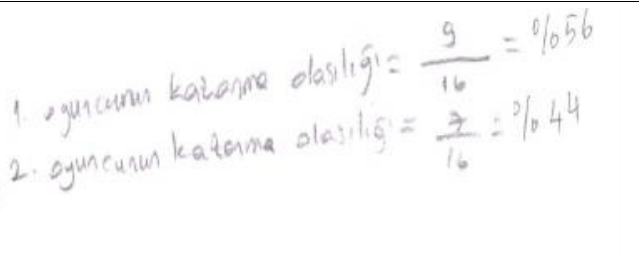 & $\begin{array}{l}\text { Some of the prospective } \\
\text { teachers proportioned the } \\
\text { number of the suitable } \\
\text { situations to the number of } \\
\text { all situations by listing all } \\
\text { situations. }\end{array}$ \\
\hline$\frac{1}{4} \cdot \frac{2}{4}+\frac{1}{4} \cdot \frac{2}{4}+\frac{1}{4} \cdot \frac{1}{4}+\frac{1}{4} \cdot \frac{1}{4}$ & $\sum_{1 . \text { oytunculatan }}^{\frac{9}{16}} 2.0$ & $\begin{array}{l}\text { Some of the prospective } \\
\text { teachers got the result by } \\
\text { finding out the probabilities } \\
\text { for suitable blood types in } \\
\text { bag } 2 \text { to match every blood } \\
\text { type in bag } 1 \text { and adding } \\
\text { them. }\end{array}$ \\
\hline
\end{tabular}

\subsection{The Findings 0 btained from the 0 pinions of the Prospective Teachers}

The first question aiming to determine the opinions of the prospective teachers was "How did you like the games you have played in probability courses so far? Did you enjoy them? Please, write down your opinions." Nearly all of the prospective teachers delivered positive opinions. Some of the quotes form those opinions are as follows:

- "Yes, it made the course more fun. I enjoyed playing the games."

- "The games were definitely fun, good and inter esting."

- "The games were related to the subjects we studied. They were both useful and entertaining. They made me reframe probability." 
- "I found them not only entertaining but also educative. They made me participate in the course more willingly."

- "We played and learned by having fun. We have understood the concepts of probability better. We have noticed our wrong opinions."

- "I think such different activities are important if we want to do student centered classes and attract attention to subjects. I really enjoyed playing the games.

- "I enjoyed playing the games. The fact that my guesses conflicted with the theoretical results increased my curiosity about the games and made me think about the subject a little more."

- "I didn't like the subject of probability much when I was at high school. The games and simulations affected me positively to take the course of probability into consideration and encouraged me to study that subject."

- "It sometimes took us long to get the result."

- "Studying probability with games becomes more enjoyable. The activities we did gave us useful information to plan student center ed courses in our career."

- "The coins flipped and dices rolled, card drawing games, pouches blown up by all the class, etc. Shortly, I enjoyed all the games we played a lot. I can say the fact that I thought I was incompetent at the subject of probability before, and that therefore I thought the course was boring has decreased thanks to this method of teaching. Especially when I noticed how our intuitions misled us, I realized the interesting aspect of probability rather than its boring side."

Unlike all these opinions, a student said

- "The games were boring, I didn't enjoy."

The second question aiming to determine the opinions of the prospective teachers was "What kind of difficulty did you have while you played the games in the classes of probability?" In this question, more than half of the prospective teachers answered that they didn't have much difficulty. Some quotes form those who said they had difficulty are as follows:

- "Everytime it came 5 or 6 when we rolled the dice, we disregarded it and rolled again, I always rolled 5 or 6 all the time. It caused the game to take long unnecessarily."

- "We were rolling the dice in the games. Because we were at the desks, the dices fell down and I had difficulty finding them. I didn't have any other difficulty."

- "I had difficulty finding theoretical probabilities."

- "At the beginning, I had difficulty making guesses and find out the theoretical probabilities. But, as I got used to the games, I had less difficulty."

- "Because we played the games in pairs, we couldn't exchange ideas enough in some games."

The third question aiming to determine the opinions of the prospective teachers was "Do you think educative games should be used in probability teaching? Why (not)?" It was seen that all of the prospective teachers had answered the question positively. Some of the quotes from those opinions are as follows:

- "Yes, most of students almost hate the subject of probability. By the help of these games, students can be enabled to learn while having fun and love the course."

- "I think they should definitely be used, because many people's experience and knowledge about probabilities in chance games is rather insufficient. That is the reason why it may be useful to learn some things by putting them into practice and have experience.

- "I definitely think so. Yes, because it is catchier to learn by seeing and practice instead of memorizing formulas." 
- "I certainly think they should be used. I think they are necessary in respect of the fact that education should be more efficient and that it be brought to students' attention."

- "Absolutely, educative games should be used in probability teaching. In this way, I find them useful in respect of the fact that, for students, they are preparation for classes, preliminary information, and remarkable."

- "Yes, I think so. Because, students may get bored if we always use the direct instruction method. We should try different ways and methods in teaching."

- "I think they should be used. Because, they give information about all the probable situations and their distribution."

- "Probability is such a subject that needs thinking extremely over it. As a matter of fact, it is also hard to materialize it. That's why I find these games useful for probability teaching."

- "Difficulty in probability is due to inability to think multilaterally. Games and simulations help get rid of that difficulty."

- "Yes, being able to see and compare the rates of the experimental and theoretical probabilities satisfies me more than doing classical calculations on paper. In addition, teaching a subject which students are afraid of in this way makes it more enjoyable."

The fourth question aiming to determine the opinions of the prospective teachers was "How could using educative games in probability teaching contribute to students?" Some of the quotes from those opinions are as follows:

- "Students get it in return for probability in everyday life."

- "By playing games of probability, students' viewpoints can change and they may comprehend it better."

- "It enables them to have more ideas about probability, and, also, it increases permanence in what they have learnt."

- "First of all, I think students can focus their attention and give the information to be wanted from them easier. Since it is an occasion on which they can realize that the subject isn't only comprised of formulas, I find it useful."

- "The students' attitude towards the subject of probability and mathematics may change positively."

- "Their intuitions towards probability may develop."

- "They could find a chance to see all the probable situations."

- "I think games could help students gain communication, reasoning and association skills."

- "It enables producing rational solutions instead of memorizing the solutions of problems. Thus, they can easily cope with the probability problems they may come across in everyday life."

The fifth question aiming to determine the opinions of the prospective teachers was "Might using games in probability teaching have any disadvantages? What, if any?" most of the prospective teachers said it mightn't have any. Very few of them said it might. Some of the quotes from those opinions and their frequencies are as follows:

- "The games may be time-consuming." (7)

- "During playing the games it may be hard to manage the classroom." (5)

- "The teacher needs to master the subject and have experience with the game." (3)

- "It may cause a noise." (3)

The sixth question aiming to determine the opinions of the prospective teachers was "What is your opinion about using material (coins, dices, cards, simulation, etc.) in probability teaching?" Some of the quotes from the opinions about the question are as follows: 
- "I liked using especially simulation, and I'm thinking of using it in my teaching career. As the number of experiments done increases, the theoretical value is approximated more and more, and learning doesn't take place by memorization; they are more convincing and significant."

- "Coins, dice and cards are useful, but simulation is much better material, because either few or multiple trials can be done."

- "I think these materials are very important and necessary. I understood it better after playing the games."

- "It will be appropriate to use them in classes because learning visually and by practice is permanent."

- "It would be better to use different material, particularly those we can see every day and have with us, such as coins. It is actually a sign that it is easy to get information easily if wished. J ust a viewpoint."

- "Learning visually and by practice is always permanent. The games we can make with coins, dices and cards always be remembered easily. So, it is useful to learn something using plenty of material."

- "It calls attention more, and we can realize that probability doesn't just consist of formulas because the fact that we practice the experimental probability recurrently approximates us to the theoretical probability."

- "Yes, I'm in favor of using such material, because learning will be much easier if there are something concrete for students, and as these materials are exactly relevant to the subject of probability, they would contribute a lot to learning."

- "Probability is more incomprehensible and difficult without material and games. To speak for myself, probability was more theoretical and incomprehensible in previous years. It is more comprehensible by the help of material."

The seventh question aiming to determine the opinions of the prospective teachers was "What should be taken into consideration when choosing educative games to use in classes?" Some of the quotes from those opinions are as follows:

- "Experimental material of is probability should be used without confusing students."

- "Games should be associated with the subject."

- "U sing time in games should be taken into consideration."

- "The explanations about games on worksheets should be clear and intelligible."

- "I think it would be better to play the games with easy to use material which are used in everyday life and available."

- "We should be careful about whether the games can achieve their purpose."

- "Games to call students' interest can be selected."

- "They should be suitable for students' levels."

- "Games should be clear, simple and educative."

- "They should enable discussing."

- "They should be economic, portable and strong."

- "The classroom and students should be organized in accordance with games."

- " Students should be encouraged to participate actively."

The eighth question aiming to determine the opinions of the prospective teachers was "Would you think of using games in teaching probability in your teaching career? Why (not)?" Some of the quotes from those opinions are as follows:

- "It would be the method for me to use, but I think I would concentrate on simulation, because anything involving technology is more interesting for me." 
- "I'm thinking of using the games played with dices and coins, because students should sometimes see the probability results with their own eyes by practicing themselves."

- "I'm absolutely thinking of it. Now that I had fun at this age, I think it would call the interest of the children of an age level that are keen on games more, and they could understand without having much difficulty."

- "I'm certainly thinking of it. C hildren learn what they need to; and they need games more at those ages. If we can make use of games in teaching the subject of probability, this is an advantage and it should be used."

- "Yes, because even I have changed my viewpoint towards the probability course at this age, after playing the games. I think it would have a much more positive effect if we apply it to students of a low age level."

- "Yes, I'm thinking of using them, because probability is an abstract subject. I think different approaches are necessary in order to understand some concepts more clearly. I also think that it contributes to students to improve their intuitions."

- "Yes, I would think of it. Probability is such a subject that can be associated with real life as a whole. I would try to teach by practice and experience, and make use of games."

- "I wouldn't think of using games frequently, because it would take long. I might sometimes use them in order to attract students' attention, consolidate what they have learnt and make the class hours' fun."

As can be seen in the quotes, the prospective teachers want to use educative games in probability teaching for various reasons when they become teachers.

And in the ninth question aiming to determine the prospective teachers' opinions, they were asked about the options they prefer to be used in probability teaching. They could make more than one choice. The findings obtained are shown in Figure 9.

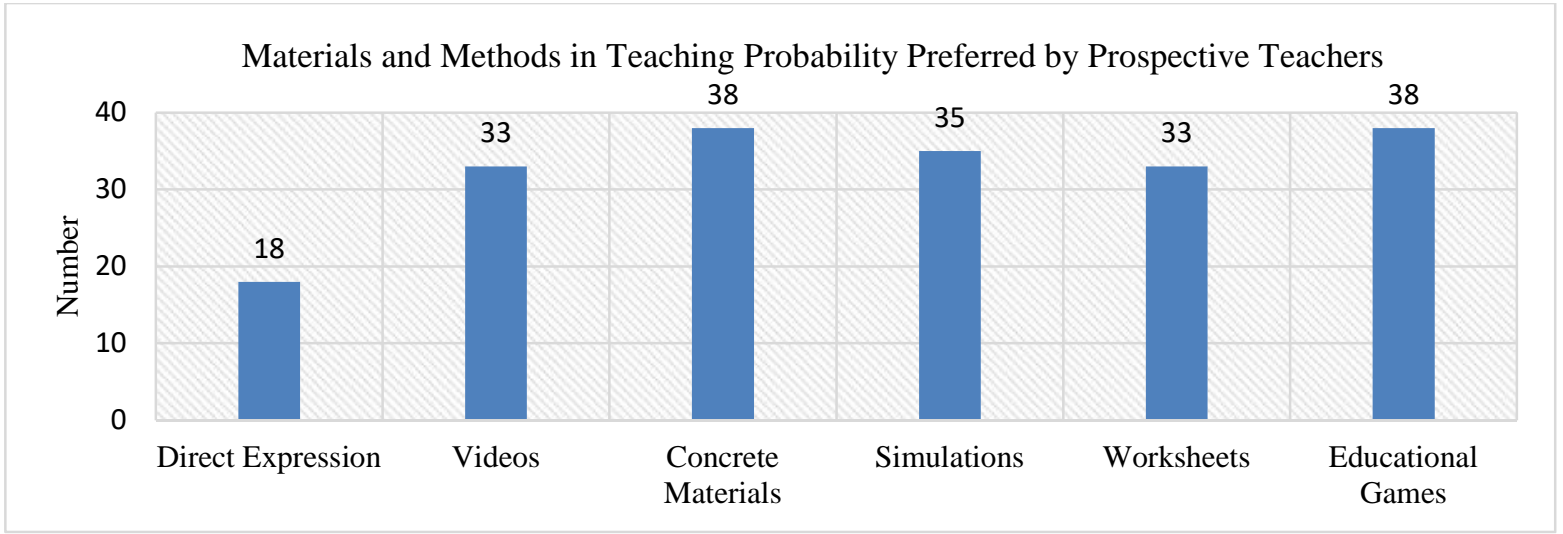

Figure 9. Materials and methods in probability teaching preferred by prospective teachers

As can be seen in Figure 9, while most of the prospective teachers stated that videos, concrete material, worksheets and educative games should be used in probability teaching, more than half of them pointed out that the direct instruction method shouldn't be used. This can be interpreted that the traditional probability teaching isn't preferable.

\section{DISCUSSION}

It was seen that the prospective teachers had difficulty in making predictions before playing the games or they made incoherent predictions. This proves that the prospective teachers couldn't develop proper strategies while making predictions and had wrong intuitions. Hence, there have been researchers who point out that there is need for enough education and support to improve 
the intuitions of both teachers and students in probability teaching (Hawkins, 1990; Batanero, Contreras, Fernandes, \& Ojeda, 2010).

On the other hand, it can be said that the explanations made after playing the games with concrete material and simulations were generally right. This case suggests that it is useful and necessary not to use an expression only dependent on theoretical knowledge but to do scientific studies enabling discussing situations in which real or realistic life conditions containing probability are supported by games and simulations. Indeed, Koparan (2016) stated that modern approaches should be used in probability teaching.

In this study, using games and simulations contributed to linking the probability knowledge of the prospective teachers to real life situations and to the coming up of the mathematical knowledge underlying the games. Indeed, Koparan (2016) stated that the visualization needed concerning the probability problems hadn't been provided in traditional environments, and that alternative learning environments were needed. However, it enabled the prospective teachers to understand the relation between the experimental and theoretical probabilities. Indeed, Batanero, Henry, \& Parzysz, (2005) pointed out that students should accept different comments in order to develop a significant perception and discover the connections between them and different contexts which any of them might be useful for.

In this study, a POE strategy-based educational gaming approach is presented in probability teaching. Researcher observations revealed that the POE strategy-based game approach could significantly increase the interest of students and their retention. That is, the POE can help prospective teachers clarify their own individual opinions and effective in promoting a durable conceptual change, as indicated by some researchers (Küçüközer, 2013; Akpınar, 2014). This means that the POE strategy is an effective way of teaching probability and is fully integrated into the game.

Prospective teachers stated that the use of play, study material, concrete material and simulation in probability teaching makes the teaching of probability more enjoyable and fun. These opinions of prospective teachers are in line with the findings obtained in the study of Kaya and Elgün (2015). Prospective teachers stated that the use of play, study material, concrete material and simulation in probability teaching makes the teaching of probability more enjoyable and fun. Prospective teachers think that the anxiety and fear of the student about the probability lesson can be reduced by the presentation of probability course with games, concrete materials and simulations in a comprehensible way in amusing learning environments. There are studies (Katmada, Mavridis, \& Tsiatso, 2014) supporting this opinion of preservice teachers and indicating that games are used in mathematics courses and thus positive changes occur in students' attitudes in courses.

It was seen that the prospective teachers' opinions about the learning situation made up are positive in general. The prospective teachers stated that the probability classes became more attractive and enjoyable with such materials as games, worksheets, simulations, videos, dices and coins. Indeed, Gürbüz (2006) stated that the fact that the subjects are generally taught in teacher centered classrooms and suitable teaching materials are missing or not used affect probability teaching negatively.

\section{CONCLUSION}

It shouldn't be forgotten that prospective teachers tend to teach however they have learnt. The role of prospective teachers is big in giving individuals basic skills associated with probability. For this reason, it is important that prospective teachers should gain different experiences associated with probability teaching at university. It is necessary that prospective teachers should know the ways to get to the probable answer using certain strategies whenever they come across any situation with probabilities, and bring this way of thinking to students as well. 
By this study, it was demonstrated how to present a subject in different ways in teacher training, how to do a didactic analysis in a similar situation, what the basic probability ideas are, and at what level to use these formulated similar situations with secondary school students. Such analyses should make an essence in teacher training with respect to mathematical and didactic viewpoint. Prospective teachers expressed that they wanted to use new approaches in this study when they would teach probability when they become teachers. However, the opinions obtained from the prospective teachers suggest that the activities analyzed in this study contributed to the knowledge of probability and probability teaching of the prospective teachers synchronously.

\section{ORCID}

Timur Koparan (iD) https://orcid.org/0000-0002-3174-2387

\section{REFERENCES}

Ahmad, W., Shafie, A., \& Latif M. (2010). Role-playing game-based learning in mathematics. Electronic J ournal of M athematics \& Technology, 4(2), 184-196.

Akpınar, E. (2014). The Use of Interactive Computer Animations Based on POE as a Presentation Tool in Primary Science Teaching. Journal of Science Education and Technology, 23(4), 527-537.

Batanero, C., Henry, M., \& Parzysz, B. (2005). The nature of chance and probability. In G. A. Jones (Eds.), Exploring probability in school: Challenges for teaching and learning, (pp. 15-37). Netherlands: Kluwer.

Batanero, C., Contreras, J. M. Fernándes, J. A. \& Ojeda, M. M. (2010). Paradoxical games as a didactic tool to train teachers in probability. Publicación en C, Reading (Eds.), Proceedings of the Eight International Conference on Teaching Statistics [CD-ROM]. Lubjana: International Association for Statistical Education. ISBN: 978-90-77713-54-9. Tipo de contribución: Trabajo referido. 4 -6 Julio 2010.

Begg, A. (1995). Statistics and the mathematical processes. Teaching Statistics, 17(2), 40-45.

Ben-Zvi, D., \& Garfield, J. (2004). The Challenge of developing statistical literacy, reasoning, and thinking, Kluwer Academic Publishers.

Borovcnik, M., \& Kapadia, R (2009). Research and developments in probability education. International Electronic J ournal of Mathematics, 4(3), 111-130.

Bragg, L. (2007). Students' conflicting attitudes towards games as a vehicle for learning mathematics: A methodological dilemma. Mathematics Education Research Journal, 19(1), 29-44.

Bulut, S., Yetkin . E., \& Kazak S. (2002). Investigation of prospective mathematics teachers'probability Achievement, Attitudes Toward Probability and Mathematics with Respect to Gender. Hacettepe U niversity J ournal of Education. 22, 21-28.

Burguillo, J. C. (2010). Using game theory and competition-based learning to stimulate student motivation and performance. Computers and Education, 55, 566-575.

Gaise (2005). G uidelines for assessment and instruction in statistics education (GAISE) report: A curriculum framework for PreK-12 statistics education. The American Statistical Association (ASA). http://www.amstat.org/education/gaise/

Gal, I. (2005). Towards "probability literacy" for all citizens: building blocks and instructional dilemmas. In G.A. Jones (Eds.) Exploring probability in school: Challenges for teaching and learning, (pp. 39-63). New York: Springer.

Gürbüz, R. (2006). Olasılık kavramlarının öğretimi için örnek çalışma yapraklarının geliştirilmesi [Development of study sheets for the teaching of probability concepts]. Çukurova U niversity J ournal of F aculty of Education, 3(1), 111-123. 
Gürbüz, R. (2008). Olasılık konusunun öğretiminde kullanılabilecek bilgisayar destekli bir materyal [A computer aided material for teaching 'probability' topic]. M ehmet Akif Ersoy U niversity J ournal of F aculty of E ducation, 8(15), 41-52.

Gürbüz, R., Erdem, E., \& Uluat B. (2014). Reflections from the Process of Game-Based Teaching of Probability. Croatian J ournal of Education, 16(3), 109-131.

Greer, G., \& Mukhopadhyay, S. (2005). Teaching and learning the mathematization of uncertainty: historical, cultural, social and political contexts. In: G.A. Jones (Eds.) Exploring probability in school: Challenges for teaching and learning, (pp. 297-324). New York: Springer.

Hamalainen, R. (2008). Designing and evaluating collaboration in a virtual game environment for vocational learning. Computers \& E ducation, 50, 98-109.

Hawkins, A. (1990). Training teachers to teach statistics. Voorburg: International Statistical Institute.

Hill, H. C., Sleep, L., Lewis, J. M., \& Ball, D. L. (2007). Assessing teachers' mathematical knowledge: What knowledge matters and what evidence counts? In F. Lester (Eds.), Second Handbook of Research on Mathematics Teaching and Learning, (pp. 111-155). Charlotte NC: Information Age Publishing.

Jones, G.A., Langrall, C.W., \& Mooney, E.S. (2007). Research in probability: responding to classroom realities. In: F.K. Lester Jr (Eds.) Second Handbook of Research on M athematics Teaching and Learning, (pp. 909-955). Reston: The National Council of Teachers of Mathematics.

Joyce, C. (2006). Predict, observe, explain (POE). http://arb.nzcer.org.nz/strategies/poe.php (accessed on 10 June 2017)

Kamii, C., \& Rummelsburg, J. (2008). Arithmetic for first graders lacking number concepts. Teaching Children M athematics, 14(7), 389-394.

Katmada, A., Mavridis, A., \& Tsiatsos, T. (2014). Implementing a gam efor supporting learning in mathe-maticss. The Electronic J ournal of e-Learning, 12(3), 230-242.

Kaya, S., \& Elgün, A. (2015). Eğitsel oyunlar ile desteklenmiş fen öğretiminin ilkokul öğrencilerinin akademik başarısına etkisi [The influence of instructional games in science teaching on primary students' achievement]. Kastamonu E ducation J ournal, 23(1), 329342.

Konold, C. \& Miller, C. (2004). TinkerPlots ${ }^{\mathrm{TM}}$ Dynamic Data Exploration 1.0. Emeryville, CA.: Key Curriculum Press.

Konold. C, Harradine A, \& Kazak S. (2007). Understanding distributions by modeling them. International J ournal of C omputers for M athematical Learning, 12(3), 217-230.

Koparan. T., \& Kaleli Yilmaz. G. (2015). The effect of simulation-based learning on prospective teachers' inference skills in teaching probability. Universal Journal of Educational Research, 3(11), 775-786.

Koparan, T. (2015). Olasılık Öğretiminde Simülasyon Kullanımı [Using similation in teaching probability]. O ndokuz M ayis U niver sity J ournal of F aculty of E ducation, 34(2), 22-36.

Koparan, T. (2016). Using simulation as a problem solving method in dice problems. British J ournal of Education, Society \& Behavioural Science, 18(1), 1-16.

Koparan, T. (2019). Examination of the dynamic software-supported learning environment in data analysis, International Journal of Mathematical Education in Science and Technology, 50(2), 277-291.

Koparan, T., \& Taylan Koparan, E. (2019). Empirical Approaches to Probability Problems: An Action Research. European Journal of Education Studies, 5(10), 100-117.

Küçüközer, H. (2013). Designing a powerful learning environment to promote durable conceptual change. Computers \& Education, 68, 482-491. 
Maxara C, \& Biehler R. (2007). Constructing stochastic simulations with a computer tool students' competencies and difficulties. In D. Pitta, Pantazi, \& P. G. Philippou (Eds.), P roceedings of the $F$ ifth Congress of the E uropean Society for Research in Mathematics E ducation. Larnaca, Cyprus.

Mills, J. (2002). Using computer simulation methods to teach statistics: A review of the literature. J ournal of Statistics Education, 10(1), 1-20.

National Council of Teachers of Mathematics (NCTM), (2000). Principles and Standards for School Mathematics. Reston, VA: National Council of Teachers of Mathematics.

Nisbet, S., \& Williams, A. (2009). Improving students' attitudes to chance with games and activities. Australian M athematics Teacher, 65(3), 25-37.

Ponte, J. P., \& Chapman, O. (2006). Mathematics teachers' knowledge and practices. In A. Gutierrez \& P. Boero (Eds.), Handbook of research on the psychology of mathematics education: Past, present and future, (pp. 461-494). Roterdham: Sense.

Stohl, H. (2005). Probability in teacher education and development. In G. Jones (Ed.). Exploring probability in schools: Challenges for teaching and learningn (345-366). New York: Springer

White, R., \& Gunstone, R. F. (1992). Prediction-Observation-Explanation. In R. White \& R. F. Gunstone, Probing understanding (pp. 44-46). London, England: The Falmer Press. 